\title{
Review of Research
}

\section{Rural Multilingual Family Engagement: Review of Research and Model of Engagement}

\author{
Maria Coady
}

Rural teachers and educators are increasingly called upon to build partnerships with families who use languages other than English in the home (US DOE, 2016). This is equally true for rural schools, where the number of multilingual families is small, and the language and cultural backgrounds of students differs from those of school. This article reviews the research on parental involvement and three common models of parental involvement. In this article, I propose a revised conceptual model for teachers and educators for rural multilingual family engagement. This article calls for increasingly refined research that addresses the sociohistorical backgrounds of families and the current sociopolitical context of multilingual family engagement. Ultimately, rural multilingual family engagement is predicated on differentiated practices, relational trust between educators and families, and attention to geospatial variation.

\section{Introduction}

Few can deny the important role that families play in the education of children. In the U.S., recent federal legislation under the Every Student Succeeds Act (ESSA) requires schools to engage families in order to support child learning (US DOE, 2016). Section 1111 of ESSA (n. P) states that Local Education Agencies (or school districts across the US) must now state how they will communicate with parents with the goal of "lowering barriers to greater participation by parents in school planning, review, and improvement experienced." Research on family engagement suggests that teachers and educational leaders communicate with families and ensure that families participate in their child's learning both in school and at home. It also presumes that schools align students' cultural and linguistic backgrounds to the students' school experiences. In other words, schools are increasingly required to communicate to parents and caregivers using languages that they understand. This requirement is especially important for families, such as immigrant families, who use languages other than English at home.

In addition to language, the cultural knowledge of families and their understanding of the how schools work and the role of teachers in child learning also affects the ways that families engage in their child's education (Moll, Amanti, Neff, \& Gonzalez, 1992). For instance, for immigrant families, their knowledge of the roles of guidance counselors, reading coaches, and language specialists in their child's education can impact their communication with key school staff and personnel in the US (Coady, 2019). In contrast, in rural settings that are characterized as university or college towns, multilingual families have higher socio-economic status and access to high levels of education (Fenning, 2019). Finally, an additional layer of complexity exists for families who reside in rural settings, because place and space (Green \& Letts, 2007) can determine access to resources, language support, physical presence in the school, and technology.

This paper examines rural multilingual family engagement from the perspective of the teacher. I use the term family engagement to reflect the broader range of activities that families participate in. It reviews the literature on parental involvement and family engagement and notes the limitations of prior research to simultaneously address issues of language diversity and rurality. This work underscores the National Rural Education Association (NREA, 2016) research priorities that aim to build a stronger research base for rural education in the US. Two of the NREA research priorities directly relate to multilingual students and family engagement: rural school and community-family relations; and teacher and leader preparation, in particular the specialized preparation for teachers of multilingual students. After describing the intersection of rurality, family, and multilingualism, this paper offers a conceptual model that builds upon the theory of praxis, that is, teacher reflection and teacher action, to prepare 
teachers and educators for rural multilingual family engagement.

\section{Review of Literature}

Family engagement is not a new concept in education, nor is its effect on student learning overly controversial. For instance, Weiss comments that there is "a skyscraper of research that supports the fact that family engagement is one of, if not the strongest predictor, of what happens to children" (Weiss, 2014, np). Educators and policymakers continue to underscore the importance of families in the educational experiences of students (Coady, 2019), and research in this area demonstrates the varying roles that families play in child learning (Jeynes, 2003).

Family engagement is particularly challenging for rural schools when families are geographically distant from each other or from community resources, centers, or the school itself. Family engagement becomes more complex when families speak and use minoritized or indigenous languages, or when teachers, leaders, and staff are un- or underprepared for linguistic diversity (Coady, 2019; Lucas, 2011).

Two issues that arise in the literature on family engagement for rural multilingual families is the "geographical blindness" that characterizes traditional, metro-centric educational policies, practices, and teacher education programs (Eppley, 2015; Roberts \& Green, 2013, p. 765). Similarly, research on family engagement continues to characterize those practices using both a monolingual orientation (Epstein, 2011; Sheridan, Kunz, Holmes, $\&$ Witte, 2017) and/or a metro-centric orientation of schools, where geography and space are absent from the pragmatic considerations of family engagement (Epstein, 2011; Henderson \& Mapp, 2002). Family home languages, cultural backgrounds, and migration experiences are complex social characteristics that should inform how educators build relationships with families and students in rural schools.

\section{The intersection of rurality, family, and multilingualism}

Rural is both place and descriptor. Scholars of rural education note the complexity of the rural (Green \& Letts, 2007; Roberts \& Green, 2013) and underscore that the rural is not a single monolith. Green and Reid (2014) argue that space, scale, and distance - all geographic elements - contribute to rurality in various ways. Distance or proximity to services and schools influences if and how families are physically present in the school environment, as well as how social and community services in and outside of school can be accessed. Noting the concept of "social cartography" which emphasizes the social processes that occur within rural places, Green and Reid describe how "geography as we mobilize it encompasses social and cultural life in particular locales" (p. 28).

Geography, space, and place intersect and are characteristics of culture. For instance, White and Corbett (2014) use the concept of the terroir, or the terrain, the complete natural environment that contributes to the essence of an object. Using the example of wine as a derivative of local soil, climate, and topography, the resulting product is something unique and rooted to its place of origin. The same grapes harvested from southwest France and South Africa will not produce the same wine. Similarly, the concept of terroir illuminates how geography, space, and place frame local cultures. Rural families and the social processes that take place within one community necessarily differ in essence from those that take place in another.

Federal definitions of rurality in the U.S. (fringe, distant, and remote) (NCES, 2006) that are frequently used to describe rural educational settings mask vast differences within different rural communities such as cultural and linguistic diversity, the funding base for schools, teacher and educator preparation, and access to technology (Arnold, Newman, Gaddy, \& Dean, 2005). Following the NCES definitions, fringe rural communities may have access to public libraries and health clinics due to their proximity to urbanized settings, whereas remote rural communities may not. Thus, within the same school district, there may be both fringe and remote schools that have distinct ways of engaging families. These geographic differences affect resources such as educator access to professional development (PD) and expertise to support and engage with multilingual students and families. Although the rural nature of schools brings challenges to the actual physical presence of families in schools and to the relationship-building process between schools and homes, rural schools hold advantages. Witte and Sheridan (2011) describe this where

Rural schools are uniquely positioned to foster and benefit from family-school partnerships. Because of their centrality within the community, rural schools routinely connect with 
families in multiple capacities as part of typical daily routines... In many rural communities, the local school building is a point of pride for the community and houses sporting and cultural events, civic activities, and shelter during severe weather. Teachers serve as coaches and club sponsors which means that they have frequent and varied contact with students at multiple age and academic levels and their families. (p. 3)

\section{Multilingual families}

Multilingual families speak and use languages other than the dominant language of the community and school. Although educational policies under ESSA require schools to engage families in child learning in the languages that families use, in practice this mandate is more complicated for rural schools (Coady, 2013), because school lack access to linguistic resources (Ruiz, 1984). Like the concept of rurality, there is wide variation across multilingual families, the languages that they use, and their sociohistorical and cultural backgrounds that reveal migration patterns. Scholars of multilingualism note repeatedly that even in urbanized settings, teachers are frequently un- or underprepared for linguistic diversity and for trends in migration patterns, such as with refugee families that affect rural schools (Coady, 2019; Daniel, 2018; Semke \& Sheridan, 2012; Terrazas, 2011; Terrazas \& Fix, 2009). In sum, the intersection between rurality, families, and multilingualism is a complex space, and unraveling the relationship between those concepts is a challenging task for rural teachers and educators (Coady, Cruz-Davis, \& Flores, 2008).

\section{Research on family engagement}

Much of the research on family engagement for multilingual families assumes a metro-centric orientation (Semke \& Sheridan, 2012), suggesting that family engagement, like other aspects of educational policies and practices, suffers from geospatial blindness. I use the term geospatial blindness by drawing from the work of Green and Letts (2007) but differentiating geographical blindness from geospatial blindness. Space itself is not neutral, and the varied distances between places have a strong effect on how rural schools, teachers, and of families participate in communities. Thus, educational policies, practices, and programs that fail to account for both geography and the space that characterizes rural schools is, in essence, blind to both. The result of geospatially blind policies requires rural teachers and educational leaders to become adept at work that is multifaceted, innovative, responsive, and committed.

\section{U.S.-based studies on family engagement}

Research on parental involvement for multilingual families highlights several educational practices that appear to be effective. These practices include: (1) communication and interactions that take place between families and educators (Deslandes et al., 1997) and that respond to the cultural and linguistic repertoires of families; (2) advocating and implementing varied types of participation in and outside of school, ranging from more traditional school events such as attendance in parent-teacher conferences to family culture fairs to home literacy events (Coady, 2009; Miedel \& Reynolds, 1999); and (3) assistance for children that supports home learning and that strengthens family relationships to support overall child well-being (Shumow \& Miller, 2001). Recent syntheses of research reveal that family engagement has a strong effect on student learning. For example, in his meta-analysis, Jeynes (2003) found that home conversations about the value of education had a strong, positive effect on student learning, even more so than traditional practices of parents making school visits or volunteering in classrooms. Among US Latinos, research has found that the concept of familismo, where families maintain close bonds with each other, encourage family obligations, and build familial support networks, influences how parents or caregivers interact with their child in school-related tasks (Niemeyer, Wong, \& Westerhaus, 2009; Sabogal, Marín, Otero-Sabogal, Marín, \& Perez-Stable, 1987).

Noted above, Jeynes (2003) conducted a metaanalysis of research related to effective parental involvement in the U.S. In his analysis of research on parental involvement (the author's term), Jeynes reviewed and analyzed 77 research studies, including students and families from culturally and linguistically diverse backgrounds. Jeynes found two main areas that appeared to significantly affect student learning. The first factor was parental (caregiver) communication with the child, including conversations related to school experiences, home learning, and the importance of education. The second factor that affected student learning was conveying high expectations of the child. Some of those high expectations involved supporting the 
students' schoolwork and expectations for future education, such as attending college. Jeynes' work shows that parental involvement has a significant and positive effect on children across different race, ethnic, social class, and linguistic groups, and more importantly that effective family engagement included non-physical participation in school settings and at school events. This is crucial information for multilingual families who reside in rural settings because of the geographic distances between the home and school.

Henderson and Mapp (2002) analyzed 51 studies related to family involvement in U.S. K-12 public schools. They also found that family engagement had a strong positive association with student achievement. Importantly, the kinds of family engagement that was most effective was that which built upon families' strengths, recognized class difference, cultural difference, and addressed specific family needs. This research is important for all educators of multilingual students, because it reinforces the concept of parental engagement as non-traditional forms of educational participation.

Research shows that various cultural groups have different concepts of family engagement. In the U.S., recent changes made to federal education laws under the Every Student Succeeds Act (ESSA) places increased expectations on the part of schools to include parents in their children's education, making this work a national priority (USDOE, 2016). Section 1111 of ESSA (n. P) states that Local Education Agencies (or school districts across the US) must now state how they will communicate with parents with the goal of "lowering barriers to greater participation by parents in school planning, review, and improvement experienced."

Depending on cultural norms and practices, some caregivers may choose to support home learning or homework, monitor their child's academic progress, and work with teachers to develop their child's academic skills. Other norms, however, differ crossculturally and illuminate a "teacher as expert" ideology, which multilingual parents would not challenge by attempting to 'teach' a child at home.

\section{International studies on family engagement}

Several additional noteworthy reviews of literature on effective parental engagement have been conducted over the past decade. For instance, Goodall \& Vorhaus (2010) conducted an extensive review of more than 1200 international articles on parental engagement (the authors' term). Their review followed a process of identifying empirical research using key terms such as parent, engagement, pupil or student, achievement, and community or family. The authors located evidence-based literature on the types of activities that parents engaged in to support child learning. They found overall that the most effective practices to support the child's learning (based on those practices associated with student learning outcomes) were home-literacy activities where parents helped or taught their child in the home setting and engaged in the use of text with them.

For multilingual families, the role of culture in family communication and engagement cannot be under underestimated. Culture frames families' beliefs about what good child rearing is, the role of the home in a child's education, and what caregivers believe they can and should do. Western orientations and expectations of family behavior in child learning are pervasive in the literature on home-school partnerships. However, new research from international settings continues to emerge and inform alternative family engagement practices. For example, in a recent study, Kim, Brown, Kim, and Fong (2018) examined urban Chinese parents' different orientations toward education participation based on being from 'poorer' or 'wealthier' homes. They analyzed surveys from 503 respondents and conducted interviews with approximately 60 individuals. In contrast to studies conducted in the West, where wealthier parents were more likely to have higher achieving children than those from poorer homes, this study found that children from lower income households had superior study habits due to their "strong achievement motivation and parents' involvement" (p. 93). In other words, Kim and colleagues found that children from low-income backgrounds were more highly motivated to study and that their parents were more invested in their child's school success.

Noted earlier, for many multilingual families the language used in the home setting neither matches the language of school nor is it the language in which literacy is taught in school (García \& Kleyn, 2016; Makalela, 2015). Multilingual families face the added challenges of not knowing or using the language of school. For example, in a study of biliteracy practices in a low-income school in South Africa, (Coady, 2019) found that reading and writing literacy were introduced to students in one language, isiZulu, in grades 1-3, while students were transitioned into all 
English literacy by grade 4 . Neither of the two languages of the school-isiZulu or English - were used in the home or the community. Rather, the community and home environments reflected 'uberlingual' practices and included the languages of Sepedi, Xhosa, French, in addition to isiZulu.

In another review of the international literature on parental involvement, Goodall and Montgomery (2014) described a three-step continuum of parental involvement that range from a parent's involvement in schools on one end to parental engagement with a child's learning on the other end. The three steps along the continuum included (1) parent involvement in school, where parents are physically present and active in traditional school-based activities; (2) parent involvement with schooling, where parents and schools exchange information either in the home or at the school; and (3) parent engagement, which has significant parental agency in a child's learning. Examples of step 3-parental engagement with child learning - included parents providing supplemental education (tuition) for their child and/or taking a leadership role in school related events. The authors noted that for parents to be "most effective... engagement needs to be rooted in the home, in an attitude that fosters learning" (p. 402). They further that

by the third phase, it is clear that parents and schools share this responsibility. A shift in agency, has occurred, a movement to a more equitable situation, and one that previous literature has shown to be of positive value for children. (p. 407)

While the shift in agency - that is, a shared responsibility for child learning - appears to support higher levels of student learning and academic outcomes, for multilingual families, this type of engagement may not only be linguistically incongruent, it may be culturally incongruent. In sum, engaging multilingual families in the context of education cannot follow a one-size-fits-all approach.

\section{Common Models of Parental Involvement}

Over the past three decades several models of parental involvement have been advanced by scholars in the field. Three notable models are included for review here: Epstein (2011), Henderson and Mapp's (2002) best practices, and the WIDA A, B, Cs (2017), the last of which focuses specifically on multilingual families. These models appear in the literature and are cited by scholars as exemplary practices for teachers. Below I review these models using a lens of rural multilingual families. I then suggest a revised conceptual model of family engagement.

\section{Epstein spheres of influence}

Epstein's model consists of three overlapping spheres - home, school, and community - and six types of involvement, which she refers to as "six types of caring" (1995, p. 14). Her research has identified a broad array of hands-on strategies and activities for schools to use with families. Several activities that engage families are advanced to build relationships between homes and schools. Epstein classifies six types of involvement:

1. Parenting - helping all families to establish home environments to support children as students

2. Communicating - designing effective schoolto-home and home-to-school communications about school programs and children's progress

3. Volunteering - recruiting and organizing parent help

4. Learning at home - providing information and ideas to families about how to help students at home with homework and other school tasks

5. Decision making - including parents in school decisions and leadership

6. Community collaborating - identifying and integrating resources and services from the community to support schools and families

The model suggests educational activities for each of the six areas of parental involvement. For example, communicating with parents, number 2 above, includes activities such as establishing conferences with parents at least once each school year. In a more recent iteration of her model of parental involvement, which Epstein and colleagues describe as 'redefinitions' for parental involvement, the scholars acknowledge that communication should include multiple channels of communication that take into consideration parents who do not speak English or the main language of school. Epstein's model underscores the need for multiple levels of school leadership in order to build parent involvement in schools. Epstein's framework for parental involvement is grounded in a western model of education that assumes parental knowledge of mainstream language and cultural practices, and that parents engage in mainstream literacy practices such 
as reading activities between the child and parent in the home.

\section{Henderson and Mapp's impact, strategies, and organizing efforts}

Two noteworthy scholars in the field of parental involvement are Henderson and Mapp (2002). In their extensive review of the research related to parental involvement, these scholars sought to understand and synthesize the research conducted on parental involvement. They followed a systematic approach to identifying empirical research studies conducted over that decade that would shed light on best practices of parental involvement. Indexed in their work, A New Wave of Evidence, Henderson and Mapp (2002) included 51 empirical studies, only a few of which relied on experimental or quasiexperimental designs. A larger number of Henderson and Mapp's identified studies were correlational. In those, the researchers made associations between parental involvement and student learning outcomes. A significant number of the studies the authors reviewed were evaluations of programs or interventions, such as parent programs funded under the US Department of Education for high poverty schools (referred to as Title I), or smaller scale projects such as 'Book Buddies'.

Findings from Henderson and Mapp's thorough analysis placed the studies in three main categories: those that investigated the impact of family and communities on student achievement; those that investigated strategies to connect schools, families and communities; and those that investigated organizing efforts to improve schools' engagement of parents and communities.

The authors identified three overarching features of high performing schools that engaged families. In those schools, successful educators:

1. focused on building trust and relationships between teachers, families and key community organizations;

2. identified, respected, and acted upon families' needs, social class, and cultural differences; and

3. embraced a shared partnership of power and responsibility with families. (Henderson \& Mapp, 2002, p. 7)

Henderson and Mapp's review noted that schools where students were performing well have high levels of family and community involvement. They argued that children whose parents talk with them about education, convey high expectations for their learning, and plan for them to continue into college or university perform best overall. Some of the main associations that negatively affected student performance included poverty, and parents having a lower level of education and low level of literacy (ability to engage with text) in the homes. For multilingual families, issues of 'feeling welcome' (Henderson \& Mapp, 2002, p. 159) affected their participation in schools and school events.

\section{WIDA A, B, Cs: Six essential areas}

The WIDA system of second language development is widely followed throughout the US. Currently, 38 states use and follow WIDA (WIDA, 2017) as a platform for supporting teachers of English learner (EL) children. Recognizing the impact of positive home-school partnerships on student learning, in recent years the WIDA group of educators and scholars expanded its work from teacher strategies with ELs to strategies with multilingual parents.

The WIDA group's approach to prepare educators for multilingual family engagement is referred to as the ABCs. The labeling (A B Cs) suggests a simplicity in the model that educators could follow. However, because practically speaking no one-size-fits all approach to family engagement is effective, they outline six essential areas in three categories (A, B and C) that educators can be aware of when working with multilingual families:

A-awareness and advocacy;

B-brokering and building trust;

C-communication and connect to learning.

The WIDA group notes that working with families requires the first step of becoming aware of who families are and building trust. Becoming aware involves educators' taking stock of their personal views of working with families and their beliefs about how parents should be involved in a child's education. Similar to Henderson and Mapp's (2002) review of research that educators' views and beliefs had a strong impact on parental involvement in schools, WIDA suggests that advocacy, the second " $\mathrm{A}$ ", is a "tool that parents and educators can use to fight injustices' (WIDA, 2017, p. 2).

Brokers are cultural informants or people with language skills and knowledge of the community who can serve as mediators between schools and families. WIDA notes that this can include cultural and linguistic brokers. Multilingual children should 
not serve as cultural brokers or interpreters on behalf of their parents or caregivers, because of the undue stress and responsibility it places on children (Orellana, 2009). Communication with multilingual families using home languages supports building trusting relationships (Coady, 2019). Finally, the WIDA group suggests that connecting parents to their child's learning is a focused and systematic effort, where educators provide families with timely and comprehensible information about their child's education.

Each of the above models underscores the need for family engagement to support student learning. The models address culture and its congruence between the home and school and they advocate for bridging schools and the home through parental activities and outreach. Epstein, and Henderson and Mapp offer suggestions for practices that support parental involvement. However, these frameworks assume a shared underlying concept of education, and are grounded in communication practices that position schools as experts. In other words, what multilingual families know and believe about education, their personal experiences with formal schooling, and the socio-historical backgrounds of families in rural settings suffers from the same geospatial blindness that characterizes teacher education programs in general.

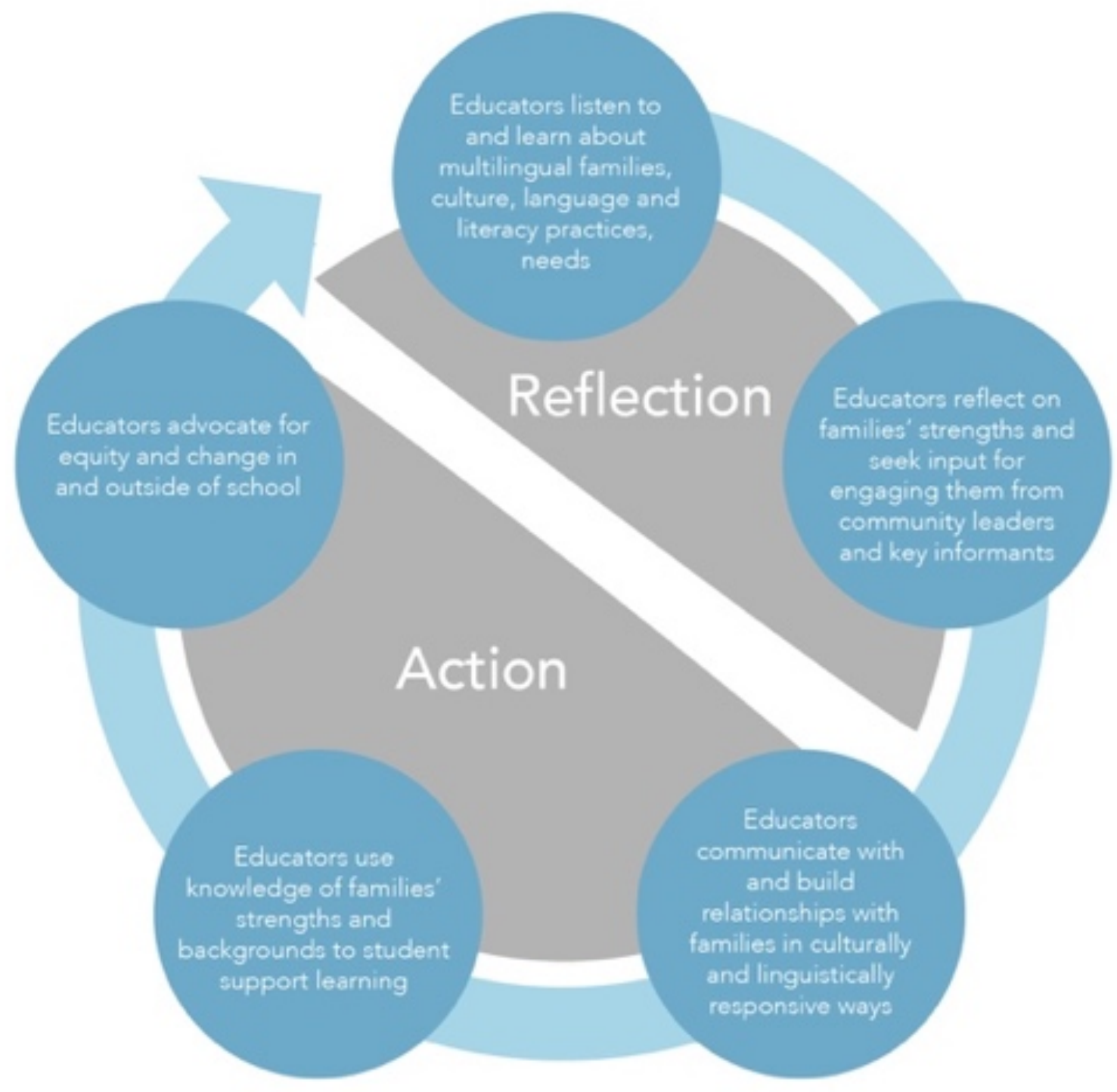

Figure 1. Rural, Multilingual Family Engagement: A Conceptual Model

Vol. 40, No. 3 The Rural Educator, journal of the National Rural Education Association 


\section{A Conceptual Model of Differentiated Family Engagement for Rural Multilingual Families}

The conceptual model aims to differentiate family engagement as a way to prepare educators for rural multilingual families. The model does not specifically address all challenges that rural educators face; rather, by allowing educators to uncover the linguistic and cultural strengths within the rural community by multilingual families, it allows for differentiated engagement for family engagement.

The circular shape and arrow represent the work of educators as an ongoing, reflective process. This begins with educators' examination of their own beliefs of family engagement and the home language, culture, and literacy practices of families. Educators connect their beliefs and knowledges of families to families' strengths, including what they do and know, and their contributions to the community. Family engagement begins by building relational trust between educators and families (Baquedano-López, Alexander, \& Hernandez, 2013; Bryk \& Schneider, 2002). The model relies on both sides of Freirean "praxis," that is, reflection and action, as interwoven and necessary features in order to transform learning. Description of the model follows with examples of reflection and action by rural educators with multilingual families.

Five components frame the model and involve (a) listening to and learning about multilingual families cultures, languages, literacy practices, and needs; (b) reflecting on families' strengths and seeking input from rural community leaders and key informants; (c) communicating with and building relationships with families in culturally and linguistically responsive and effective ways; (d) using knowledge of families' strengths and backgrounds to support student learning in the classroom; and (e) advocating for equity and change in and outside of rural school. These are not separate sequential steps but rather components of an overall system of preparing educators for family engagement.

\section{Educators listen to and learn from and about families}

One of the first components of rural multilingual family engagement is to learn about and from families, their home languages and literacy practices, and cultural backgrounds and needs, with the goal of establishing relationships. The work of educators as listeners and learners seems anathema, however, to traditional models of teachers as "knowers" of information (Freire, 1993). Three subcomponents frame this concept: educator self-reflection; personal engagement with families; and building trust and care.

Educator self-reflection refers to educators who have a personal commitment to rural communities and understand how they function. Because of the nature of rural education, teachers frequently live within the community that they work (Eppley, 2015). This puts teachers at an advantage when seeking knowledge about families' needs and the resources within the community. Yet teachers' own views of families influence their work. For example, Baquedando-López, Alexander, and Hernandez (2013) reviewed literature on parental involvement. They found that "parental participation in schools is strongly shaped by [teachers'] perceptions of parents' background, the roles expected of them by school administrators and teachers, and by the organizations that fund... parental involvement programs" (p. 150). In other words, the authors found that what educators think about and expect from parents has a strong impact on actual parental participation. Questioning assumptions about multilingual families and reshaping educator beliefs from deficit and negative ideologies and stereotypes to actual knowing families is a first step toward building trust, care, and engagement. In our rural setting, we began by asking teachers to reflect on what they recalled about their own family's participation in their schooling, then to describe that through the generation of poetry. We also examined the language used by multilingual families and began to build school resources using technology (translation services) and community members (from rural health agencies). After reflecting and acting on language uses by families, the school's electronic placard was changed to show English on one side and the same message in Spanish on the other side.

\section{Educators reflect on families' strengths and seek input}

A second component is the task of educators to reflect on families' strengths and seek input from community members in order to learn more about families. Educators learn about families through their students, through home visits, learning about immigrant families' home countries via self-study, and by taking stock of local industries, labor markets, commerce, and medical agencies. Educators can also learn about family and local migration patterns and 
the history of the community and local political that build a positive "context of reception" for immigrants (Stepick \& Dutton Stepick, 2009).

Panferov (2010) interviewed two case study parents whose personal views of literacy framed their interactions with their children. She found that parents were intent and supportive of their children's literacy development. She noted that engaging parents as advocates in the home, where they interact most with their children, is more likely to support students' success in school. These studies point to the importance for educators to view rural, multilingual families from a strengths-based ideology whose resources contribute to rural schools and community settings. In our community, prior to reflecting and building relationships with families, educators assumed that the immigrant parents had low levels of education. After examining and reflecting upon the school's and families' linguistic resources, the school principal decided to transform a traditional mainstream, inclusive fourth grade classroom, with one to three multilingual students, into a selfcontained bilingual classroom with their most experienced teacher, who had been teacher of the year. When the families came to "meet the teacher" night at the beginning of the school year, the teachers learned through the bilingual paraprofessionals and community advocates that several of the immigrant parents held master's degrees in their field, one in computer technology and another in agriculture. Other parents were highly skilled in law. The knowledge about families' strengths was learned when the school staff demonstrated to families and students that their home languages were valued in the bilingual classroom.

\section{Educators communicate with and build relationships with families in culturally and linguistically responsive ways}

One way that educators act with and on behalf of families is to communicate with families in languages that they understand. Despite US US rules under ESSA that require the use of home languages in communication with families wherever possible, too many examples demonstrate that English-only policies continue to characterize home-school interactions. For example, in their study of one school district, Coady and colleagues (2019) interviewed teachers, educational leaders, and parents regarding the use of multiple languages for homeschool communication. They found that teachers were unfamiliar with federal policies on the use of home languages and that district level administrators did not make accessible important translation services and software that would allow teachers to translate school materials for parents.

There is evidence, however, that effective school policies and practices follow "non-traditional" types of communication with multilingual families. For example, Arias and Morillo-Campbell (2008) describe the barriers that non-English speaking families face when attempting to integrate and communicate with schools. They offer several insights into the challenges and possibilities of effective family engagement, noting the charged antiimmigrant context of multilingual families in the US. Non-traditional parent involvement strategies include developing reciprocal understandings of schools and families; ensuring that cultural strengths of families and communities are embedded in the curriculum; promoting parental advocacy; and implementing culturally and linguistically appropriate practices in all aspects of communication.

Linguistically and culturally responsive communication practices also include inviting families to the school site or identifying spaces in the rural community where families feel safe to attend. Churches or community centers may be more friendly, welcoming, and nurturing spaces for multilingual families than schools (Coady, 2013). Because rural settings frequently have few community spaces in which to hold meetings, schools play a key role (Hansen-Thomas, Richins, Kakkar, \& Okeyo, 2016).

This component is characterized by ongoing, regular, and systematic approaches to communicating with families. Educators learn the that languages that families use and understand the pragmatics features of a language such as distance between speakers and various social status or gender roles when communicating. Before taking action, reflection on previous experiences may be necessary to ensure that teacher and educator actions are appropriate and effective. Continuous teacher reflection and assessment of this component is essential, because multilingual families in rural settings may be migratory and move frequently in and out of the community. Updating communication methods, phone numbers, contact information is part of the work to remain connected to families. In our rural community, the school recognized that their communication with literate families could take place using text messages. The third, fourth, and fifth grade 
teams of teachers signed up for "Remind" (https://remind.com), a text-based communication system that translates English texts into home languages and back. For non-literate families, access to interpreters and community members who speak their families' languages can be kept near families' information. Building connections with rural community health centers may also assist.

\section{Educators use knowledge of families' strengths and backgrounds to support student learning}

In today's multilingual, global environment, it is increasingly common to hear multiple languages on television, the Internet, and in rural settings where migrants and refugees increasingly settle (Suro \& Singer, 2002). Makalela (2015) states that in order for multilingual students to succeed academically, educators must first ensure that students' and families' identities are affirmed and reflected in school curricula, activities, and events. Educator practices that affirm students' languages and literacy include learning across multiple linguistic repertoires of students (García \& Kleyn, 2016), 'active bilingualism' (Cummins, 2018), multiple literacies, and teaching for cross-language transfer (Coady \& Ariza, 2010; Cummins, 2000). Some ways that schools can generate welcoming spaces, in addition to multilingual signage, is to ensure that the school's social media is representative of the diversity in the community. Mentoring relationships can be built without added cost between teachers, parents, and community advocates. Our rural community advocates build a network of promotoras, community health lay workers, who network within the rural community to provide support to others.

\section{Educators advocate for equity and change in and outside of school}

Finally, this component of a comprehensive model of rural multilingual family engagement builds upon the concept of critical consciousness or conscientização (Freire, 1993; Freire \& Macdeo, 2001) and the local contexts in which families live and schools function. In 'contested' spaces of social, economic, and political inequity, engaging with families means that educators listen and respond to families' experiences and their stated needs. This is where advocacy happens inside the classroom and outside of the school gates. Engagement with rural multilingual families should be formed on the basis of reciprocal, trusting relationships (Bryk \&
Schneider, 2002) and mutuality. Parents and families should not be recipients but rather active partners, when possibly, in order to build and maintain long term relationships. For example, we learned that dental care and health care services were expensive and out of reach in our community but important for newcomer migratory families from Guatemala and from Puerto Rico after hurricane Maria. A local rural school connected with a rural women's health agency to identify bilingual mental health services for the displaced children who had suffered the loss of their biological parents at the same time.

Family engagement in this context reflects the reality of families' lived experiences, and knowledge of and response to the negative discourses and stereotypes of multilingual families. Informed, differentiated family engagement is possible through critical teacher reflection, conscientização and action in partnership with educators, advocates, and community agencies in rural settings. Educators who differentiate engagement with rural multilingual families use their knowledge of the socio-historic and political context of families, situated and rooted in the local community, to make informed instructional decisions that support student learning. Families contribute to the overall social environment of the local community, the economy, and the way that the community functions.

\section{Conclusion}

This conceptual model of differentiated family engagement for rural, multilingual families entails both reflection and action. Listening, learning, and reflecting on family strengths and needs encompass the first part of the model. Acting with and on behalf of families involves communicating, using information to support learning, and advocating for change. Based on this review and the conceptual model proposed, several recommendations for research can be made: (1) more refined demographic data on rural multilingual families and students such as student and family language(s), cultural knowledge base, and histories in rural settings; (2) innovative approaches to family engagement that use non-traditional conceptual frameworks and that include a wide array of practices that are culturally and linguistically responsive to families; and (3) research on the ways that teachers and educational leaders can be prepared to engage multilingual families, such as the different phases proposed in the conceptual model described here. 
This article aimed to complicate the landscape of family engagement to include multilingual families who have been historically overlooked in the research base in education in general and in rural education in particular, and associate multilingual family engagement with teacher and educator preparation. These two areas - family engagement and specialized teacher and educator preparationare directly related to the NREA's research priorities through 2021. Scholars and educators must refine research questions that investigate the complexity of the school and home in order to understand the nuanced and differentiated ways in which families' backgrounds can effectively be affirmed through schools.

The model described above aimed to illuminate how rural multilingual family engagement requires multiple layers of learning about families and understanding and responding to their needs; and second to guide educators in building relationships and trust with rural multilingual families. This model of teacher education and rural multilingual family engagement draws upon the socio historical, political, and contextual factors that affect families, children, and communities in order for educators to differentiate family engagement policies and practices within their local school settings. Rural teacher education and rural schools hold promise for reconceptualizing the ways schools work, affirm, and can establish communities that affirm multilingual families. Teacher education that responds to these unique needs has the potential to make a difference in the lives of diverse students.

\section{References}

Arias, M. B., \& Morillo-Campbell, M. (2008).

Promoting ELL parental involvement: Challenges in contested times. Boulder, CO: Education Policy Research Unit. Retrieved from http://epsl.asu.edu/epru/documents/EPSL-0801250-EPRU.pdf

Arnold, M. L., Newman, J. H., Gaddy, D. D., \& Dean, C. B. (2005). A look at the condition of rural education research: Setting a direction for future research. Journal of Research in Rural Education, 20(6), 1-25.

Baquedano-López, P., Alexander, R. A. \& Hernandez, S. J. (2013). Equity issues in parental and community involvement in schools: What teacher educators need to know. Review of Research in Education, 37, 149-182. doi: 10.3102/0091732X12459718

Byrk, A. S., \& Schneider, B. (2002). Trust in schools: A score resource for improvement. New York: Russell Sage Foundation.

Coady, M. R. (2009). "Solamente libros importantes": Literacy practices and ideologies of migrant farmworking families in north central Florida. In G. Li (Ed.), Multicultural families, home literacies and mainstream schooling (pp. 113-128). Charlotte, NC: New Age.

Coady, M. R. (2013). Using families' ways of knowing to enhance student learning. In E. Amatea (Ed.) Building culturally-responsive family-school partnerships: from theory to practice (pp. 227-245). ( $2^{\text {nd }}$ ed.). Upper Saddle River, NJ: Pearson.
Coady, M. R. (2019). Connecting school and the multilingual home: Theory and practice for rural educators. Bristol, UK: Multilingual Matters.

Coady, M. R., \& Ariza, E. (2010). Struggling for meaning and identity (and a passing grade): High-stakes writing in English as a second language. MEXTESOL, 34(1), 11-27.

Coady, M. R., Cruz-Davis, J., \& Flores, C. (2008). Personalmente: Home-school communication practices with (im)migrant families in north Florida. Bilingual Research Journal, 31, 251270. doi:10.1080/15235880802640714

Cummins, J. (2000). Language, power, and pedagogy: Bilingual children in the crossfire. Clevedon, UK: Multilingual Matters. doi: 10.21832/9781853596773

Cummins, J. (2018). Multilingualism in education: Intersections of research, theory, policy, and practice. Clevedon, UK: Multilingual Matters.

Daniel, S. (2018). Resettled refugee youth leveraging their out-of-school literacy practices to accomplish schoolwork. Mind, Culture, and Activity. doi: 10.1080/10749039.2018.1481092

Deslandes, R., Royer, E., Turcotte, D. \& Bertrand, R. (1997). School achievement at the secondary level: Influence of parenting style and parent involvement in schooling. McGill Journal of Education, 32, 191-207. https://mje.mcgill.ca/article/view/8377 
Eppley, K. (2015). "Hey, I saw your grandparents at Walmart": Teacher education for rural schools and communities. The Teacher Educator, 50(1), 67-86. doi: 10.1080/08878730.2014.975061

Epstein, J. 1995. School/Family/Community Partnerships: Caring for the Children we Share. Phi Delta Kappan 76, 701-712. doi: 10.4324/9780429493133

Epstein, J. L. (2011). School, family, and community partnerships: Preparing educators and improving schools ( $2^{\text {nd }}$ Ed.) Philadelphia, PA: Westview Press.

Fenning, A. (2019). Engaging international students in rural communities. Paper and panel presentation at the International TESOL Convention. Atlanta, GA.

Freire, P. (1993). Pedagogy of the oppressed. New York: Continuum.

Freire, A. M. A. \& Macedo, D. (2001). The Paulo Freire reader. New York: Continuum.

García, O., \& Kleyn, T. (Eds.). (2016). Translanguaging with multilingual students: learning from classroom moments. New York: Routledge. doi: 10.4324/9781315695242

Glover, T. A., Nugent, G. C., Chumney, F. L., Ihlo, T., Shapiro, E. S., Guard, K., Koziol, N., \& Bovaird, J. (2016). Investigating rural teachers' professional development, instructional knowledge, and classroom practice. Journal of Research in Rural Education, 31(3), 1-16.

Goodall, J., \& Montgomery, C. (2014). Parental involvement to parental engagement: A continuum. Educational Review, 66(4), 399-410. doiI: 10.1080/00131911.2013.781576

Goodall, J., \& Vorhaus, J. (2010). Review of best practice in parental engagement. Department for Education, UK.

Green, B., \& Letts, W. (2007). Space, equity and rural education: A 'trialectical' account. (pp. 5776). In K. N. Gulson \& C. Symes (eds.) Spatial Theories of Education: Policy and Geography Matter. New York, NY: Routledge.

Green, B., \& Reid, J.-A. (2014). Social cartography and rural education: Researching space(s) and place(s). In S. White, \& M. Corbett (Eds.), Doing educational research in rural settings: Methodological issues, international perspectives and practical solutions (pp. 26-40). New York, NY: Routledge.

Hansen-Thomas, H., Richins, L, G., Kakkar, K., \& Okeyo, C. (2016). I do not feel I am properly trained to help them! Rural teachers' perceptions of challenges and needs with English-language learners. Professional Development in Education, 42(2), 308-324. doi: 10.1080/19415257.2014.973528

Henderson, A. T., \& Mapp, K. L. (2002). A new wave of evidence: The impact of school, family and community connections on student achievement. Austin, TX: Southwest Educational Development Laboratory. Retrieved from www.sedl.org/connections/resources/evidence.pd $\mathrm{f}$

Kim, S. W, Brown, K., Kim, E. J., \& Fong, V. L. (2018). "Poorer children study better": How urban Chinese young adults perceive relationships between wealth and academic achievement. Comparative Education Review, 62(1), 84-102. doi: 10.1086/695534

Jeynes, W. H. (2003). A meta-analysis: The effects of parental involvement on minority children's academic achievement. Education and Urban Society, 35(2), 202-218.

Lucas, T. (2011). Preparing teachers for linguistically diverse classrooms: A resource for teacher educators. New York: Routledge/Taylor $\&$ Francis.

Makalela, L. (2015). Bilingualism in South Africa: reconnecting with Ubuntu translanguaging. In O. García and A. Lin (Eds.), Encyclopedia of bilingualism and bilingual education. New York: Springer. doi: 10.1007/978-3-319-02258-1_14

Miedel, W. T. \& Reynolds, A. J. (1999). Parent involvement in early intervention for disadvantaged children: Does it matter? Journal of School Psychology, 37, 379-402.

Moll, L. C., Amanti, C., Neff, D., \& Gonzalez, N. (1992). Funds of knowledge for teaching:

Using a qualitative approach to connect homes and classrooms. Theory into Practice, 31(2), 132141. doi: 10.1080/00405849209543534.

National Center for Education Statistics (NCES). (2016). Fast facts on English language learners. Retrieved from https://nces.ed.gov/fastfacts/display.asp?id=96

National Rural Education Association (NREA). Ten research priorities. Retrieved from http://www.nrea.net/Research_and_Publications

Niemeyer, A. E., Wong, M. M., \& Westerhaus, K. J. (2009). Parental involvement, familismo, and academic performance in Hispanic and Caucasian adolescents. North American Journal of Psychology, 11(3), 613-631. 
Orellana, M.F. (2009) Translating childhoods: Immigrant youth, language, and culture. New Brunswick, NJ: Rutgers University Press.

Panferov, S. (2010). Increasing ELL parental involvement in our schools: Learning from the parents. Theory into Practice, 49(2), 106-112. doi: $10.1080 / 00405841003626551$

Roberts, P., \& Green, B. (2013). Researching rural places: On social justice and rural education. Qualitative Inquiry, 19(10), 765-774. doi: $10.1177 / 1077800413503795$.

Ruiz, R. (1984). Orientations in language planning: Problem, right, or resource. NABE Journal, 8(2), 15-34.

Sabogal, F., Marín, G., Otero-Sabogal, R., Marín, B., \& Perez-Stable, E.J. (1987). Hispanic familism and acculturation: What changes and what doesn't? Hispanic Journal of Behavioral Sciences, 9, 397-412. doi: $10.1177 / 07399863870094003$

Semke, C. A., \& Sheridan, S. M. (2012). Familyschool connections in rural educational settings: A systematic review of the empirical literature. School Community Journal, 22(1), 21-48.

Sheridan, S.M., Kunz, G.M., Holmes, S. and Witte, A. (2017) Family-school partnerships in rural communities: Benefits, exemplars and future research. In G.C. Nugent, G.M. Kunz, S.M. Sheridan, T.A. Glover and L.L. Knoche (eds) Rural Education Research in the United States: State of the Science and Emerging Directions (pp. 269-290). Switzerland: Springer International. doi: 10.1007/978-3-319-42940$3 \_14$

Shumow, L. \& Miller, J. D. (2001). Parents' at-home and at-school academic involvement with young adolescents. Journal of Early Adolescence, 21, 68-91. doi: 10.1177/0272431601021001004.

Stepick, A., \& Dutton Stepick, C. (2009). Contexts of reception and feelings of belonging. Forum:
Qualitative Social Research, 10(3), Art 15. Retrieved http://www.qualitativeresearch.net/index.php/fqs/article/view/1366/286 3

Suro R., \& Singer, A. 2002. Latino Growth in Metropolitan America: Changing Patterns, New Locations. Washington, DC: The Brookings Institution.

Terrazas, A. (2011). Immigrants in new-destination states. Migration Information Source. Migration Policy Institute: Washington, DC. Retrieved from https://www.migrationpolicy.org/article/immigra nts-new-destination-states\#1

Terrazas A., \& Fix, M. (2009). The Binational Option: Meeting the Instructional Needs of Limited English Proficient Students.

Washington, DC: Migration Policy Institute.

US Department of Education. (2016). Every Student Succeeds Act of 2015. Retrieved from https://www.ed.gov/essa?src=rn

Weiss, H. (2014). Transatlantic forum on inclusive early years. $3^{\text {rd }}$ Meeting. Lisbon, Portugal. Retrieved from https://www.youtube.com/watch?v=Pv7VgChSg $8 \mathrm{~s} \&$ feature $=$ share $\&$ list $=\mathrm{PL} 17 \mathrm{gcPJzCrQWAyCa} 5$ Lt5mOCKbDFTb4QN7

White, S., \& Corbett, M. (Eds.) (2014). Doing educational research in rural settings: Methodological issues, international perspectives, and practical solutions. New York: Routledge. doi: 10.4324/9781315778440

WIDA (2017) The A, B, Cs of family engagement. See https://wida.wisc.edu/resources/abcs-familyengagement

Witte A. L., \& Sheridan, S. M. (2011). Family Engagement in Rural Schools (R2Ed Working Paper No. 2011-2). Retrieved from the National Center for Research on Rural Education website: http://r2ed.unl.edu

\section{About the Author:}

Maria Coady is a professor of ESOL and Bilingual Education at the University of Florida. Maria can be reached at mcoady@coe.ufl.edu.

\section{Suggested Citation:}

Coady, M. (2019). Rural multilingual family engagement: Review of research and model of engagement. The Rural Educator, 40(3), 1-13. doi:10.35608/ruraled.v40i3.545 